Article

\title{
Travel Health Knowledge, Attitudes, and Practices Among Community Pharmacists in Japan
}

\author{
Atsushi Sato 1 \\ 1 London Drugs Pharmacy Gibsons Canada \\ * Correspondence: asato@londondrugs.com
}

\begin{abstract}
Background: Travel medicine practice has not been a part of practice in the community pharmacies in Japan. However, it's getting more common for pharmacists to run travel clinic in North America. With ongoing globalization, Japanese pharmacists might be practicing travel medicine in future. This descriptive study is to examine the current knowledge, attitudes, and practices among Japanese community pharmacists. (2) Methods: Invitation to the study was sent to all pharmacies or corporates listed on Nippon Pharmacist Association member list plus one another large size pharmacy chain that was not member of NPhA. Community pharmacists working under those companies received a weblink to the survey. The survey was conducted from June to July 2017 by online questionnaire. (3) Results: The selfdeclared knowledge level of infectious diseases as well as travel vaccinations was generally low. The frequency of correct answer of the antibiotic resistance in South East Asia was 48.5\%. Knowledge level of qunine resistance to Plasmodium falciparum malaria in Ghana and Nicaragua was very low. (4) Conclusions: Japanese community pharmacists are not familiar with travel related infectious diseases and vaccines used in travel medicine. The knowledge on the antibiotic resistance in traveler's diarrhea and malaria prophylaxis was all low that is consistent with low degree of exposure to travel health questions from patients in daily practice and low percentage of intention to earn travel health certificates.
\end{abstract}

Keywords: community pharmacy; pharmacist; KAP 4; travel health

\section{Introduction}

The number of international travellers has been increasing continuously last half century and this trend is expected to continue. In 1950, 25 million international tourist arrivals were reported worldwide but this number increased to 1326 millions in 2017 [1].

Clinical pharmacists in the Kaiser Permanente (an American integrated managed care consortium) in Colorado Region started travel consultation via telephone in 1991 [2]. Since then, it's getting more and more common for American pharmacists to offer pre-travel health care services. Vaccination at pharmacies became popular in 1990s in the United States after the American Pharmacists Association (APhA) first launched their National Certificate Training Program for pharmacists on immunization delivery in 1996 [3]. The Canadian pharmacists started to administer influenza vaccine in 2008 in British Columbia and Alberta, then pharmacist run travel clinic became popular. The pharmacists in Ontario had some time lag but finally became authorized to administer travel vaccines as of 2016. Pharmacists in California can furnish medications for malaria prophylaxis and travellers diarrhea. In Canada, pharmacists in Alberta also has prescribing right for the same range of prescription medications whereas fellows in other provinces in Canada don't.

On the other hand, community pharmacy practice in Japan has been consistently conservative and has not gained expanded scope of practice such as immunization, prescribing right, and travel consultation. Having increasing number of tourists across the world, with particular trend of welcoming more inbound tourists in Japan [4], the pharmacists in the county need to focus on travel medicine for future practice at global standard. However, is is unknown if there were any reasons behind for pharmacist being not involved in travel medicine field. The purpose of this descriptive study is to examine the attitudes, practices and knowledge level of Japanese pharmacists working in community pharmacies with regard to travel medicine to proceed forward for possible travel medicine practice in the future. 


\section{Materials and Methods}

\subsection{Questionnaire}

A questionnaire was designed to cover demographic information, actual pharmacy practice, attitude toward certification in travel health, and to assess body knowledge of travel medicine among Japanese community pharmacists.

Respondents were asked about basic information such as gender, age group, years of experience as a community pharmacist, and also about the frequency of coming across questions related travel medicine from patients to examine current practice. Certification status in travel medicine was inquired to determine the attitude of pharmacists where selections were the Japanese Society of Travel Medicine (JSTM), Japanese Society of Travel and Health, (JSTH), and/or the International Society of Travel Medicine (ISTM).

Familiarity with infectious diseases and vaccines commonly discussed in travel medicine was assessed by asking respondents to self-declare the confidence level using a 4-point Likert scale (very familiar, somewhat familiar, somewhat unfamiliar, and very unfamiliar).

Three case scenarios were set to assess knowledge on drug resistance. These were generated with reference to the study conducted by Kogelman [5]. A question was to determine the knowledge of fluoroquinoloneresistant Campylobacter in South East Asia by asking "which group of antibiotic is known to be resistant to Campylobacter?". The answer choices were fluoroquinolones, macrolides, no resistance, and others. Other two cases were to identify knowledge level on malaria prophylaxis with and without chloroquine-resistant Plasmodium falciparum malaria. Case scenario 2 and 3 stated "which medications would you choose for malaria prophylaxis for traveler to Ghana (Case 2) and Nicaragua (Case 3)". Choices of medications were atovaquone/proguanil, mefloquin, doxycycline, quinine, primaquine, no prophylaxis. Multiple answers were permitted in these case based questions.

\subsection{Participants and survey period}

An invitation to complete an anonymous web-based survey was sent via e-mail to registered pharmacies and corporates of Nippon (which means Japan) Pharmacy Association (NPhA) plus one another large size pharmacy chain that was not member of NPhA. With cases of corporate registrants, the invitation and weblink was sent to the appropriate person at headquarter of the company then weblink was forwarded to their pharmacists. Contact information was obtained from the directory on the NPhA website. Period of this survey was from June 24, 2017 to July 23, 2017.

\subsection{Statistical analysis}

All results are presented descriptively and results were analyzed using a frequency count. Both partial and complete responses were analyzed, and consequently the denominator varies for some questions. When 4-point Likert scale was used to obtain response from participants, selections of "very familiar" and "somewhat familiar" were combined for better interpretability.

\section{Results}

\subsubsection{Characteristics of respondents}

Email was sent to 215 pharmacies and corporates to request participation to the study out of which 14 responses were received. The response rate to the invitation was $6.5 \%$. Then, 205 pharmacists took surgery either fully or partially. Of the 205 respondents to the questionnaire, the number of male was $106(51.7 \%)$ and female was $99(48.3 \%)$. The age group of 30-39 occupied 52\% of all who answered, followed by 40-49 $(26.5 \%)$ and 50-59 (13.2\%). Years of experience as a pharmacist was equal in 0-10 (38.7\%) and 11-20 (38.2\%), followed by $21-30(19.6 \%), 31$ and more (3.4\%). (Table 1$)$.

Table 1. Demographics of participants

\begin{tabular}{ccc}
\hline & Characteristic & Frequency $(\mathbf{n}=\mathbf{2 0 5})$ \\
\hline Gender & Male & $106(51.7 \%)$
\end{tabular}


Female

Age

$20 \sim 29$

$30 \sim 39$

$40 \sim 49$

$50 \sim 59$

$60 \sim 69$

Not specified

Years of experience as a

pharmacist

$0-10$

$11-20$

$21-30$

31 and more

Not specified
$99(48.3 \%)$

$14(6.9 \%)$

$106(52 \%)$

$54(26.5 \%)$

$27(13.2 \%)$

$3(1.5 \%)$

$1(0.4 \%)$

$79(38.7 \%)$

$78(38.2 \%)$

$40(19.6 \%)$

$7(3.4 \%)$

$1(0.4 \%)$

\subsection{Frequency of receiving travel health related questions}

Almost all respondents (204 of 205) were receiving travel health questions anywhere from 0-5 times per month on average. There was only one pharmacist who reported the average frequency of 6-10 times per month. None of respondents was getting more than 10 times of travel related question per month.

Table 2. Average frequency of receiving travel health related questions

\begin{tabular}{cc}
\hline Number of questions per month & Frequency $(\mathrm{n}=205)$ \\
\hline $0-5$ & $204(99.5 \%)$ \\
$6-10$ & $1(0.5 \%)$
\end{tabular}

\subsection{Current status and future desire for travel health certification}

There are two academic societies in Japan offering travel health certificate that are the Japanese Society of Travel and Health (JSTH) and the Japanese Society of Travel Medicine (JSTM). Only two pharmacists had JSTM certificate in travel health. There was no pharmacist who held the knowledge certificate by the International Society of Travel Medicine (ISTM).

Table 3. Current status of travel health certification

\begin{tabular}{ccc}
\hline Certification body & $\begin{array}{c}\text { Frequency }(\mathrm{n}=205)^{*} \\
\text { Current }\end{array}$ & $\begin{array}{c}\text { Frequency }(\mathrm{n}=201)^{*} \\
\text { Future desire }\end{array}$ \\
\hline None & $203(99 \%)$ & $175(87.1 \%)$ \\
$\begin{array}{l}\text { Japanese Society of Travel } \\
\text { Medicine (JSTM) }\end{array}$ & $2(1 \%)$ & $21(10.4 \%)$ \\
$\begin{array}{l}\text { Japanese Society of Travel and } \\
\text { Health (JSTH) }\end{array}$ & 0 & $10(5 \%)$
\end{tabular}


International Society of Travel Medicine (ISTM)
0

$9(4.5 \%)$

*Multiple answers were permitted

\subsubsection{Familiarity with travel associated infectious diseases}

The sum of very familiar and somewhat familiar with travel related infectious diseases was highest with hepatitis A $(n=205,39.5 \%)$ followed by Japanese encephalitis (31.7\%), rabies $(31.2 \%)$, malaria $(27.3 \%)$, traveler's diarrhea (26.8\%), meningococcal meningitis (20.5\%), typhoid fever (16.6\%), then yellow fever (9.8\%) (Figure 1).

Figure.1 Percentage of very familiar + somewhat familiar (travel related diseases) $(n=205)$

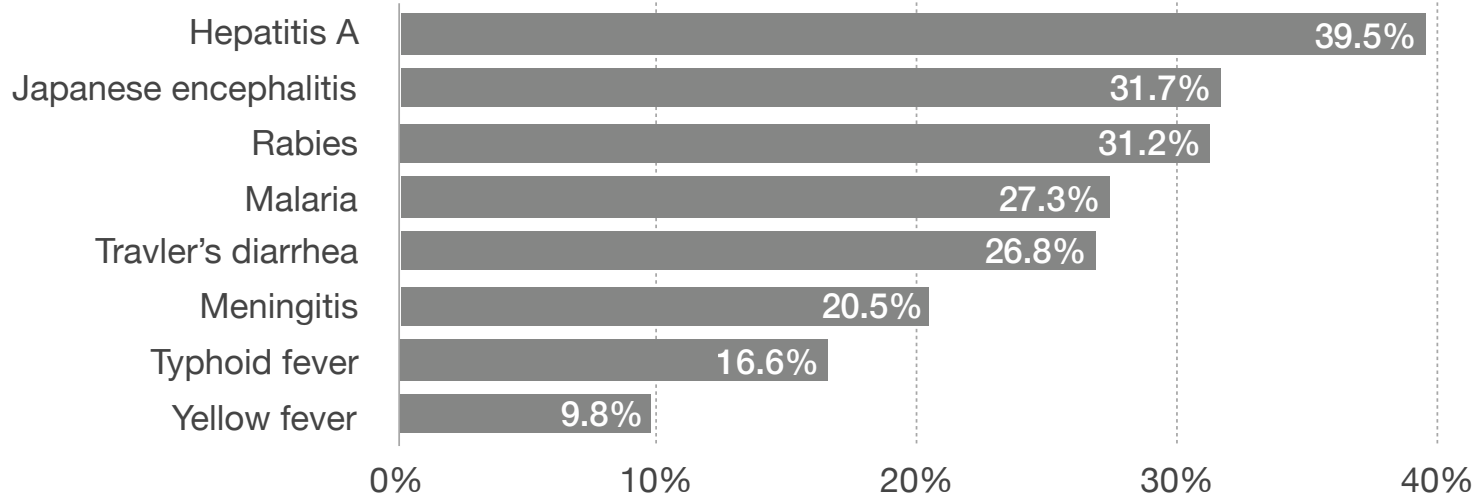

\subsubsection{Familiarity with travel vaccines}

Self-declared familiarity (very familiar + somewhat familiar in ) with travel vaccine was highest with influenza $(n=205,86.8 \%)$ followed by measles $(53.7 \%)$, polio $(43.6 \%)$, tetanus $(37.0 \%)$, Japanese encephalitis $(33.2 \%)$, rabies $(22.1 \%)$, hepatitis A $(17.6 \%)$, meningitis $(10.8 \%)$, yellow fever $(7.8 \%)$, and typhoid fiver $(4.9 \%)$ (Figure 2).

Figure.2 Percentage of very familiar + somewhat familiar (vaccines) $(n=205)$

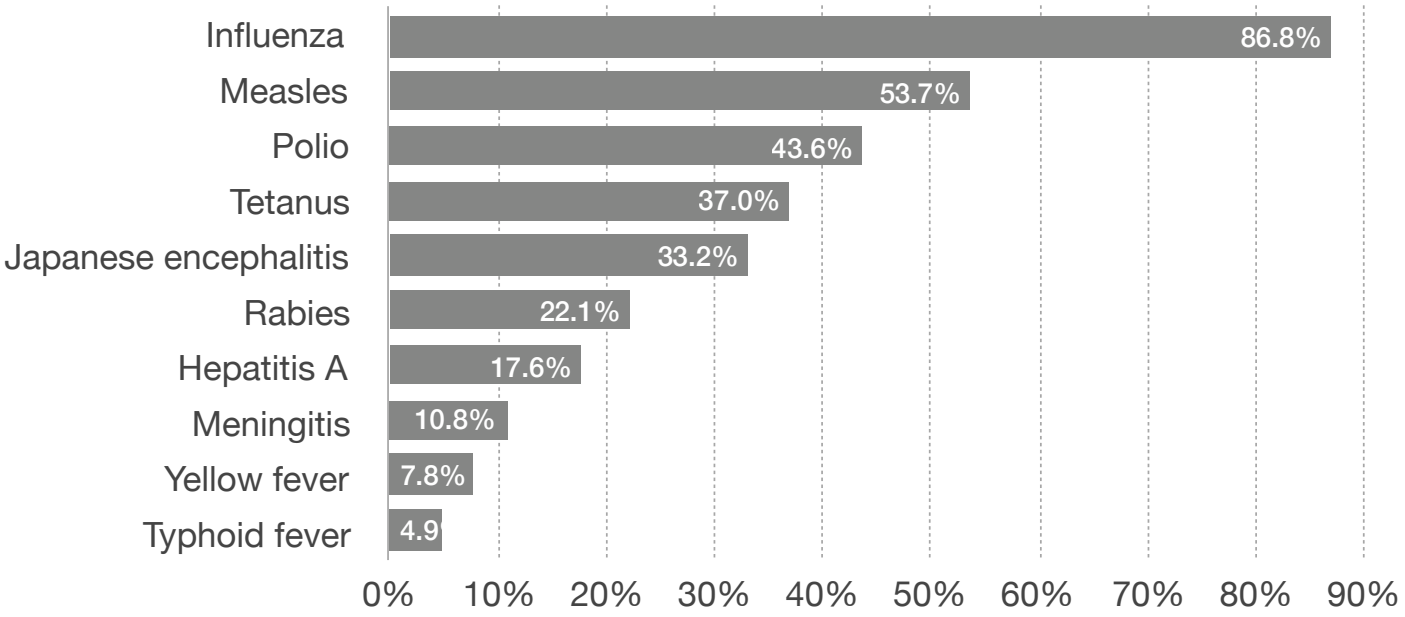


Table 3 shows the knowledge level of antibiotic resistance to Campylobacter in South East Asia. There were 171 participants selected at least one answer in this question and 34 skipped to answer. The frequency of selection for fluoroquinolone which was the correct answer was 83 (48.5\%) followed by macrolide of 79 (46.2\%) and no resistance of $6(3.5 \%)$. The overall correct answer rate for this question was $40 \%$.

Table 3. Knowledge assessment on antibiotic resistance to Campylobacter in South East

Asisa

Frequency $(\mathrm{n}=171)^{*}$

Fluoroquinolones

Macrolides

No resistance
$83(48.5 \%)$

$79(46.2 \%)$

$6(3.5 \%)$

*Multiple answers were permitted for these questions

\subsection{Knowledge assessment on the malaria prophylaxis in Ghana and Nicaragua}

The result of the knowledge assessment on malaria prophylaxis is shown in Figure 3. There were 37 participants who skipped answering for Ghana and 46 for Nicaragua out of 205 participants. The frequency of drug selection showed the same tendency for both Ghana and Nicaragua where the highest was atovaquone/ proguanil (Ghana $50 \%$ vs. Nicaragua $49.1 \%$ ) followed by mefloquin (44.6\% vs. $44.7 \%$ ), doxycycline $(30.4 \%$ vs. $35.2 \%$ ), quinine $(28.6 \%$ vs. $26.4 \%$ ), primaquine (both $11.3 \%)$, and no prophylaxis $(2.4 \%$ vs. $7.6 \%)$. The expected answer to this question was not to choose quinine for travellers to Ghana, however, $28.6 \%$ of respondents chose quinine as appropriate prophylaxis agent.

\section{Discussion}

\section{Figure.3 Selection of malaria prophylaxis in Ghana and Nicaragua (\%)(Ghana; $n=168$, Nicaragua; $n=159$ )}

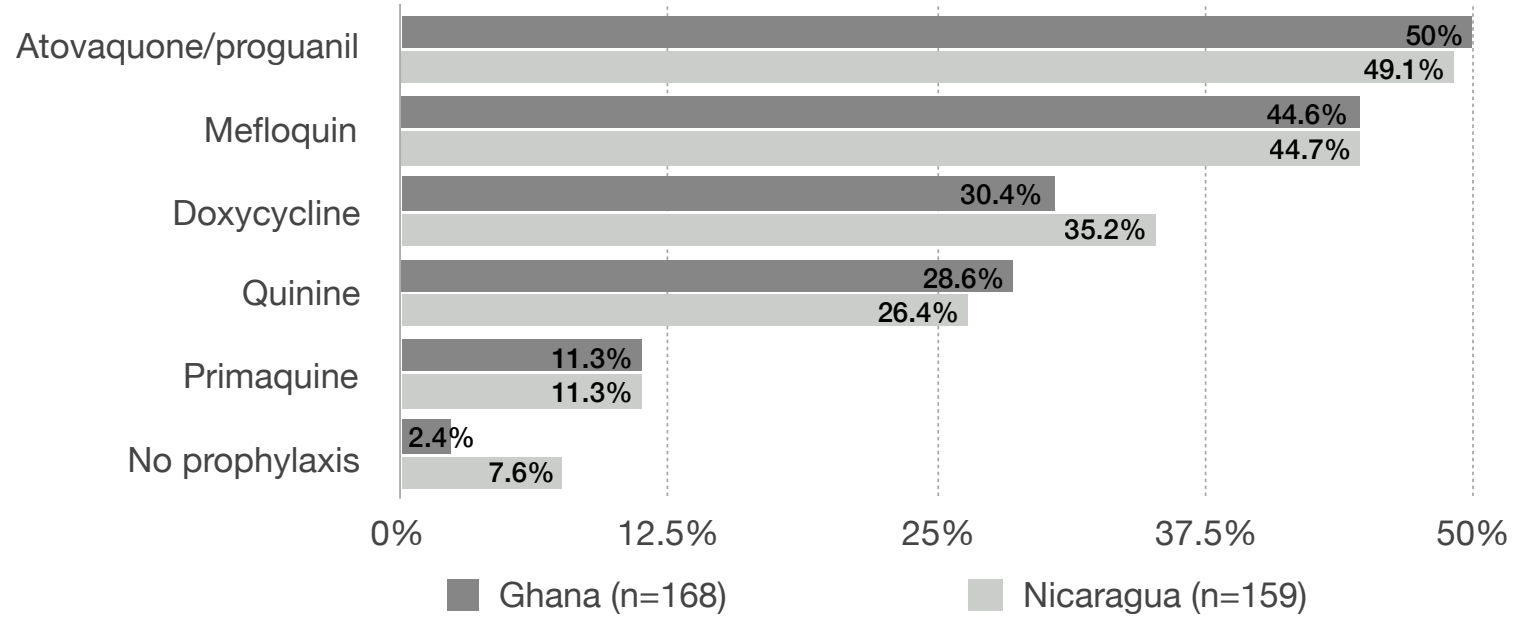

\subsection{Current situation of travel clinics in Japan}

The population of Japan is 126 million in 2018 and the number of outbound travellers has been levelling off between 16 million to 18 million last twenty years [6,7]. There were 45 records returned upon searching travel clinics in Japan on the online clinic directory of International Society of Travel Medicine as of Aug. 31, 2019 [8]. The actual number of health care facilities is less because some of health care providers work at the 
same medical facilities. For reference, there are 352 listings in Canada on the ISTM clinic directory where population is a little over 37 million and 12.8 million trips were made to overseas countries in 2017 [8,9].

There is a domestic version of online directory of health care providers certified by the Japanese Society of Travel and Health (JSTH)(http://JSTH.umin.jp/) where 142 names were listed as of Jun 21, 2019. Also there are only 22 yellow fever vaccination centres listed on the website of Ministry of Health, Labor and Welfare [10] in comparison to 206 in British Columbia and 269 in Ontario respectively in Canada [11].

Of note, there was only one hospital pharmacist in Japan listed on the ITSM travel clinic directory. Also, only 4 pharmacists were found on the JSTH's directory where three of them work in the hospital. These numbers may not be accurate because the listing is on a voluntary basis, however, this is quite consistent with the result of this study (Table 3) which comes from some uniqueness of travel clinic system in Japan.

Possible explanation to this situation is that Japanese travel clinics are run by the medical doctors in the hospital or private clinic where vaccines are dispensed and administered by nurses or physicians on site. Therefore, community pharmacies don't get to see these vaccines being administered to travel clinic clientele. Another issue is that many vaccines used at travel clinics in North America and Europe are not approved in Japan. Accordingly, particular vaccines such as cholera, tick-borne encephalitis, and typhoid fever vaccine are being imported by the doctors or their agents privately from overseas [12]. Community pharmacists are not involved in this importation process, therefore, the opportunity for them to come across these vaccines is virtually zero. The situation is different for pharmacists working in hospital in Japan if any physician runs travel clinic in the same facility where pharmacists are in charge of ordering, receiving, and storing vaccines that are imported from overseas. This study did not include hospital pharmacists but they could have some more knowledge on travellers vaccines because they handle the products. The whole problem created by a limited number of travel health providers and availability of vaccines has led to the low travel health awareness of oversea travellers as well as higher number of certain infectious diseases such as hepatitis A and typhoid fever in Nepal reported in the past $[13,14,15]$.

\subsection{Current situation of pharmacist and pharmacies in Japan}

In order to expand the coverage of pre-travel health advice in Japan, community pharmacists can potentially play a big role if they are willing to acquire solid body knowledge of travel medicine. The number of community pharmacies in Japan reached 59,000 in 2017 after having steady increase over a decade [16,17] .which presumably happened to serve more of aging population in the country. But this also looks like an excellent opportunity to provide wider coverage of travel health service by taking advantage of nationwide infrastructure of pharmacies.

This study indicated the Japanese community pharmacists don't have enough overall knowledge on travel related infectious diseases, travel vaccines, antimicrobial resistance, and malaria prophylaxis. This could mean there is lack of education or training system in place where low frequency of travel health questions and low level of interest are associated even though more than 16 million people travel internationally from Japan.

Most community pharmacists did not show interest toward obtaining certificate in future in according to the result but there could be some reasons. One possibility is there are two academic societies in Japan covering the same area that are JSTH and JSTM. The preceding small group of the JSTH started in 1996 whereas the JSTM was set up in 2001 after one year of preparation [18,19]. Author presented at the annual conference of JSTH in 2017 and attended in 2018 and 2019 but never joined JSTM's conference which was because of networking with JSTH members [20]. Otherwise, it is difficult to find differences in their activities from the official websites of JSTH and JSTM [21-22]. Both JSTH and JSTM provide one-day training course followed by the certificate exam every year. Each set of course and exam was developed just like a mini version of the ISTM Travel Medicine Review And Update Course and Certificate in Travel Health ${ }^{\mathrm{TM}}$ (CTH®). Having chances of earning domestic travel health certificate is a good thing because of several reasons. First, majority of Japanese pharmacists don't speak practical level of English, hence, it is quite difficult to pass CTH ${ }^{\circledR}$ exam which is all in English. Also Japanese pharmacists might not be willing to travel for the course or the exam by ISTM if that is not the knowledge that can be applied in daily practice as shown in the result of frequency of travel health questions. 
It is important to remember that travel medicine deals not only with outbound travellers but also with inbound tourists. At the time of writing, Japan is soon going to host some of international mass gathering events that are the Rugby World Cup from September to November 2019 at venues all across the country, the Olympic and Paralympic game in Tokyo in 2020, then the Expo Osaka Kansai in 2025. Beside these events, the number of inbound tourists to Japan increased 5 folds from 2011 (6.2 million) to 2018 (31.2 million) with a government project to enhance economy with tourism [23]. This figure is expected to hike up toward goals of 40 million in 2020 and 60 million in 2030 in according to the government's strategy plan [23]. Also, Japanese government revised immigration policy in April 2019 to get foreign workers under new visa system which is primarily due to worsening of labor shortages in the country with rapidly aging population [24]. All of these factors can contribute to importation of infectious diseases. Also, global warming adds up just as dengue fever outbroke in Yoyogi park located in central Tokyo in 2014 since 1945 and 4 cases of Japanese encephalitis were reported in 2016 on the island of Nagasaki region which is not common disease to see naturally occurring $[25,26]$. This is why more pharmacists need to learn and practice travel medicine that cover knowledge of international travellers out of and into the country. Having over 59,000 access points across the country, community pharmacists in Japan are the front-line health care professional who can educate general public on how to prevent these infectious diseases and on what to do when someone develops symptoms of suspected infections. The result of study showed that close to $90 \%$ of participants had good knowledge of influenza vaccine that implies pharmacists are willing to learn on the vaccine if the threat is close to themselves.

\subsection{Barriers in Japan and Experience in North America}

The pharmacy practice in Japan has been very conservative traditionally. The most recent big change goes back to 1990s where the function of dispensing medication for outpatients was separated from hospitals and medical clinics. Until then, pharmacists in the hospital were filling hundreds of prescriptions every day for outpatients without pharmacy assistants or technicians due to tight regulations that limited technical dispensing task only to pharmacists. Hence, pharmacists were not involved in medication management very much. With the concept of pharmaceutical care originated in North America in 1980s, the situation changed a lot and many pharmacies are built outside of medical facilities. Nowadays, pharmacists are playing a vital role in medication management of patients in communities just like the colleague in North America do.

However, there is not much more happening in terms of expansion of scope of practice. Japanese pharmacists are not authorized to give any immunization which started in the United States in 1996 with the American Pharmaceutical (now Pharmacists) Association (APhA) launching its nationally recognized immunization training program for pharmacists [3]. There was time lag between states, however, pharmacists obtained authority to administer immunizations in all 50 states, the District of Columbia, and Puerto Rico [27]. The scope of practice of Canadian pharmacists expanded after getting authorization for immunization first in British Columbia and Alberta in 2009 [28]. This was started to help not just doctors and nurses to administer influenza vaccine but also the public for better access to the vaccines to prevent spread of pandemic H1N1 influenza. It did not take much time afterward to establish travel clinic service by adding pre-travel health advice with inoculation of travel vaccinations. Timing of initiating travel vaccination was different between provinces, however, Ontario which has the biggest population in Canada allowed pharmacists to give varieties of travel vaccines to public in 2016 [29].

There have been accumulating reports to indicate clients' positive experience with travel clinic service provided by pharmacists. Pharmacists providing services in pre-travel health clinics can have substantial impact on the health of patients traveling internationally [30]. Having proper training and certification in travel medicine such as ISTM's CTH ${ }^{\circledR}$, pharmacist-run travel clinic can provide consistent evidence-based care and improve patient compliance compared to primary care providers without special training [31]. In Alberta, Canada, where authorized pharmacists can prescribe medications, positive patient satisfaction and health status were reported after pharmacist-performed pre-travel consultation [32].

Japanese Pharmacy Association has envisioned the future in its "The Future Vision of Pharmacists" issued in 2013 that trained pharmacists are giving immunization to enhance the immunization rate of public [33]. At the same time, there might have been several barriers for Japanese pharmacists to overcome. The biggest thing is minimum advocacy even after seeing successful experience in United States and Canada. There might be more of practical concerns that hold up the introduction of immunization by pharmacists and these could be the same as North American pharmacists think. Foong discussed obstacles in pharmacist 
immunization such as an increased workload of pharmacists, disturbance in workflow, patient safety, and inconsistency of scope of practice not giving other intramuscular injections than vaccines [34]. Also Houle discussed barriers in pharmacists' uptake of immunization scope expansion in Ontario, Canada, that are awareness of pharmacists scope, clinical knowledge, inability to prescribe for pharmacies without medical directive and remuneration [35]. Having these factors expected, there are many considerations for Japanese ministry before expanding pharmacists' scope of practice to immunization.

Even without immunization authority, pharmacists can always start learning about travel health related diseases, vaccines, and antimicrobial resistance (AMR) as there is much room left to grow in according to the result of this research. Especially, the AMR has been discussed a lot not just in the travel medicine but also medicine in general at global level. Japanese government created a guideline on antibiotic use in 2016 in response to World Health Organization's statement to make world-wide effort to prevent further spread of the AMR [36]. With this global focus on the anti-microbial use, the awareness and clinical knowledge of Japanese pharmacists on AMR such as fluoroquinolones and quinine as in survey might improve in the future. However, the difficulties in Japanese travel medicine are time lag from other counties in drug approval and the approved indication of drugs which is particularly notable for medications used in malaria prophylaxis. For example, atovaquone/proguanil was approved in Japan in 2012 as opposed to 2000 in the Unites States [37,38]. Primaquine was introduced to the Japanese market in 2016 after discussed as a drug with high medical needs whereas this drug was developed and approved in 1952 in the United States [39,40]. Also the approved indication of primaquine in Japan was only for eradication of liver hypnozoite stages of $P$. Vivax malaria and not as prophylaxis [41]. Thus, Japanese pharmacists have not had the same level of exposure to these medications as North American pharmacists unless there are doctors who specialize in tropical or travel medicine in neighbourhood or pharmacist holds travel medicine certificate. The idea of malaria cases in this study was to identify awareness of quinine resistance in different countries in the world, however, the result showed necessity of more learning in this area.

The figures showing willingness to earn travel medicine certificate didn't seem to be high from this study, however, simple math with 60,000 pharmacies in Japan can possibly generate more than 9000 travel health certificate holder in future. Japanese pharmacists who are not able to give immunization still have potential to implement quality patient care through sound knowledge of travel medicine. With that in mind, follow up research is expected in future for better result in knowledge, attitude, and practice of travel medicine among Japanese pharmacists in the community.

\section{Conclusions}

This study revealed Japanese pharmacists in community have low level of exposure to travel medicine given the circumstance of how travel clinics are run in the country. At the same time, there is much to learn about travel related diseases, vaccines, antibiotic resistance, and malaria prophylaxis.

\section{Patents}

None

Funding: This research received no external funding.

Conflicts of Interest: The author declare no conflict of interest.

\section{References}

1. Roser M. Tourism. Available online. https://ourworldindata.org/tourism (accessed on 24 September 2019)

2. Jackson A.B.; Humphries T.L.; Nelson K.M.; Helling D.K. Clinical pharmacy travel medicine services: a new frontier. Ann Pharmacother. 2004, 38(12), 2160-2165.

3. Hogue M.D.; Grabenstein J.D.; Foster S.L.; Rothholz M.C. Pharmacist involvement with vaccinations: a decade of professional advancement. J Am Pharm Assoc 2006, 46, 168-82.

4. Japan Tourism Statistics. Japan National Tourism Organization. Available online: https://statistics.jnto.go.jp/en/ graph/\#graph--inbound--travelers--transition (accessed on 24 September 2019) 
5. Kogelman L.; Barnett E.D.; Chen L.H.; Quinn E.; Yanni E.; Wilson M.E.; Benoit C.; Karchmer A.W.; Ooi W.W.; Jentes E.S.; Hamer D.H. Knowledge, attitudes, and practices of US practitioners who provide pre-travel advice. J Travel Med. 2014, 21(2), 104-14

6. Statistics Bureau of Japan. Current Population Estimates as of October 1, 2018. Available online: https:// www.stat.go.jp/english/data/jinsui/2018np/index.html (accessed on 24 Sep member 2019)

7. Japan National Tourism Organization. Trends in Japanese Overseas Travelers by Year. Available online: https:// statistics.jnto.go.jp/en/graph/\#graph--outbound--outgoing--transition (accessed on 24 September 2019)

8. International Society of Travel Medicine Online Clinic Directory. Available online: https://www.istm.org/ AF_CstmClinicDirectory.asp (accessed on 1 September 2019)

9. Travel between Canada and other countries, December 2017. Available online: https://www150.statcan.gc.ca/n1/ daily-quotidien/180220/dq180220c-eng.htm (accessed on 24 September 2019)

10. Quarantine information office of Ministry of Health, Labor and Welfare of Japan. Available online: https:// www.forth.go.jp/moreinfo/vaccination.html? (Japanese)(accessed on 24 September 2019)

11. Yellow Fever Vaccination Centres in Canada. Government of Canada. Available online: https://www.canada.ca/en/ public-health/services/travel-health/yellow-fever.html (accessed on 1 September 2019)

12. Hamada A. Past, present and future of travel medicine in Japan. Travel Med and Infect Dis. 2011, 9(4), 187-91.

13. Namikawa K.; Iida T.; Ouchi K.; Kimura M. Knowledge, attitudes, and practices of Japanese travelers on infectious disease risks and immunization uptake. J Travel Med. 2010, 17(3), 171-5.

14. Basnyat B.; Pokhrel G.; Cohen Y. The Japanese need travel vaccinations. J Travel Med. 2000, $7(1), 37$.

15. Thapa R.; Banskota N.; Pokharel J.; Subedi B.H.; Basnyat B. Another typhoid patient from Japan. J Travel Med. 2010, 17(3), 199-200.

16. Ministry of Health, Labour and Welfare of Japan. Summary of statistics 2017. Available online: https:// www.mhlw.go.jp/toukei/list/36-19a.html (Japanese)(accessed on 1 September 2019)

17. Cabinet office of Japan. Analysis of fee structure of community pharmacies. Available online: https:// www5.cao.go.jp/keizai3/2017/08seisakukadai14-0.pdf (Japanese)(accessed on 1 September 2019)

18. Japanese Society of Travel and Health. Available online: http://JSTH.umin.jp/ (Japanese)(accessed on 1 September 2019)

19. Japanese Society of Travel Medicine. History of JSTM. Available online: http://jstm.gr.jp/history/ (Japanese) (accessed on 1 September 2019)

20. Abstract of Global Health Conference 2017. Available online: https://endai.umin.ac.jp/cgi-open-bin/ojac/search/ ojac_search.cgi?cond=\%27A00071-00016-10096\%27\&condtion=A00071-00016\&\&parm=shuukai $\quad$ (Japanese) (accessed on 1 September 2019)

21. The Japanese Society of Travel and Health. About JSTH. Available online: http://JSTH.umin.jp/concept.html (Japanese)(accessed on 24 September 2019)

22. The Japanese Travel Medicine Society. About JSTM. Available online: http://jstm.gr.jp (Japanese)(accessed on 24 September 2019)

23. Meeting of the Council for a Tourism Vision to Support the Future of Japan. New Tourism Strategy to Invigorate the Japanese Economy March 30, 2016. Available online: https://www.mlit.go.jp/common/001172615.pdf (accessed on 24 September 2019)

24. Japan Times. Is Japan becoming a country of immigration? Available online: https://www.japantimes.co.jp/opinion/ 2019/06/26/commentary/japan-commentary/japan-becoming-country-immigration/\#.XYpIOiOZOu4 (accessed on 24 September 2019)

25. National Institute of Infectious Diseases. Local transmission of dengue, Japan. Available online: https:// www.niid.go.jp/niid/en/survei/2292-idwr/idwr-article-en/4973-idwrc-1434-en.html (accessed on 1 September 2019)

26. National Institute of Infectious Diseases. Japanese encephalitis, Japan, 2007-2016. Available online: https:// www.niid.go.jp/niid/en/iasr-vol33-e/865-iasr/7483-450te.html (accessed on 1 September 2019)

27. Weaver K.K. Pharmacist-administered immunizations: What does your state allow? Available online: https:// www.pharmacist.com/article/pharmacist-administered-immunizations-what-does-your-state-allow?rel=0 (accessed on 24 September 2019)

28. Fletcher A.; Marra F.; Bartlett G.; Kaczorowski J. Immunization Programs: The Role of Pharmacists in British Columbia, Canada. Available online: https://www.mjmmed.com/article?articleID=4 (accessed on 24 September 2019)

29. Government of Ontario. Making It Easier to Get Your Travel Vaccines. Available online: https://news.ontario.ca/ mohltc/en/2016/12/ontario-making-it-easier-to-get-your-travel-vaccines.html (accessed on 24 September 2019) 
30. Tran D.; Gatewood S.; Moczygemba L.R.; Stanley D.D.; Goode J.V. Evaluating health outcomes following a pharmacist-provided comprehensive pretravel health clinic in a supermarket pharmacy. J Am Pharm Assoc, 2015, 55.2, 143-152.

31. Durham M.J.; Goad J.A.; Neinstein L.S.; Lou M.A. Comparison of pharmacist travel-health specialists' versus primary care providers' recommendations for travel-related medications, vaccinations, and patient compliance in a college health setting. J Travel Med, 2010, 18.1, 20-25.

32. Houle S.K.D.; Bascom C.; Rosenthalc M. Clinical outcomes and satisfaction with a pharmacist-managed travel clinic in Alberta, Canada. Travel Med and Infec Dis, 2018, 23, 21-26.

33. Japanese pharmaceutical Association. The Future Vision of Pharmacists. Available online: https:// www.nichiyaku.or.jp/assets/pdf/vision.pdf (accessed on 24 September 2019)

34. Foong E.A.; Edwards D.J.; Houle S.K.D.; Grindrod K.A. Ready or not? Pharmacist perceptions of a changing injection scope of practice before it happens. Can Pharm J. 2017, 150(6), 387-396.

35. Houle S.K.D.; Kozlovsky K.; Fernandes H.V.J.; Rosenberg-Yunger Z. Uptake of Travel Health Services by Community Pharmacies and Patients Following Pharmacist Immunization Scope Expansion in Ontario, Canada. Pharmacy, 2019, 7(2), 35.

36. Government of Japan. National Action Plan on Antimicrobial Resistance 2016-2020. Available online: https:// www.kantei.go.jp/jp/singi/kokusai_kansen/pdf/ (accessed on 1 September 2019)

37. GlaxoSmithKline. Press release; Approval of Malarone ${ }^{\circledR}$. Available online: https://jp.gsk.com/jp/media/pressreleases/2012/07-p1000757/ (accessed on 24 September 2019)

38. U.S. Food and Drug Administration. Drug Approval Package of Malarone®. Available online: https:// www.accessdata.fda.gov/drugsatfda_docs/nda/2000/021078_malarone.cfm (accessed on 1 September 2019)

39. Sanofi. Press release. Available online: https://www.sanofi.co.jp/-/media/Project/One-Sanofi-Web/Websites/AsiaPacific/Sanofi-JP/Home/press-releases/PDF/2016/201603282.pdf (accessed on 24 September 2019)

40. U.S. Food and Drug Administration. All Approvals January 1952. Available online: https://www.accessdata.fda.gov/

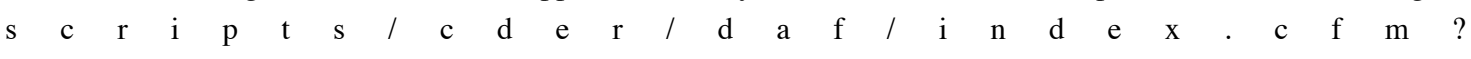
event=reportsSearch.process\&rptName=1\&reportSelectMonth=1\&reportSelectYear=1952\&nav (accessed on 24 September 2019)

41. Sanofi. Product monograph of Primaquine. Available online: https://pins.japic.or.jp/pdf/newPINS/00066295.pdf (Japanese)(accessed on 24 September 2019) 